\title{
Comparison of Grounding Grid Parameters Between Copper and Galvanized Flat Steel
}

\author{
Yue $\mathrm{Yu}^{1}$,Yanjun $\mathrm{Li}^{1}$, Dehong Wang ${ }^{2}$, Rongtian $\mathrm{Du}^{3 *}$, Chongqing $\mathrm{Jiao}^{3}$, and Jiwei Sun ${ }^{1}$ \\ ${ }^{I}$ State Key Laboratory of Power Grid Safety and Energy Conservation, Relay Protection Research Department, China Electric Power Research Institute, \\ Beijing, 100192, China \\ ${ }^{2}$ State Grid Zhejiang Electric Power Co., Ltd. Research Institute, China \\ ${ }^{3}$ State Key Laboratory of Alternate Electric Power System with Renewable Energy Sources, North China Electric Power University, Beijing, 102206, \\ China
}

\begin{abstract}
In the intelligent substation, the shell of the secondary equipment is connected to the ground grid locally. When the short circuit fault current is injected into the grounding grid to cause the ground potential rise, the potential difference between the two points of the grounding grid will affect the normal operation of the secondary equipment. In this paper, aiming at the grounding grid of a $220 \mathrm{kV}$ substation, the grounding impedance, ground potential rise and ground potential difference between galvanized flat steel and copper grounding grid are calculated by using CDEGS software. The results show that the copper ground grid has a significant effect on reducing the potential difference of the ground grid.
\end{abstract}

\section{Introduction}

In recent years, with the intelligence of substations, a large number of secondary devices are distributed near primary high voltage devices such as high voltage switches and busbars[1].The shell of secondary equipment is usually grounded nearby and connected through secondary cables. When a grounding fault occurs, the fault current injected into the grounding grid causes the grounding grid potential to rise, and there is a ground potential difference between different points in the grounding grid[2-3]. The potential difference can be applied to both ends of the secondary cable, and then form a disturbance voltage at the port of the secondary cable. The disturbance voltage can add noise to the normal signal, which may lead to the misoperation of the secondary equipment in serious case. In order to meet the needs of future intelligent substation planning and construction, it is necessary to study the characteristics of ground potential difference between two points on the conductor of grounding grid.

A numerical calculation method of ground potential difference interference based on transmission line frequency domain method is proposed in reference[4]. Based on the idea of field-circuit combination, a new method for calculating grounding parameters of grounding grid is proposed in reference[5], which analyzes and calculates the grounding impedance and ground potential difference of grounding grid under power frequency. The relationship between insulation potential difference of substation secondary system and grounding grid potential rise is discussed in reference[6].

Usually, the main grounding grid material of the substation will choose galvanized flat steel. In this paper, aiming at the grounding grid of a $220 \mathrm{kV}$ substation, using CDEGS software, galvanized flat steel and pure copper are selected as grounding grid materials for modeling, and the grounding impedance, ground potential rise and ground potential difference between two points of ground grid with different materials are calculated and analyzed. The results show that the copper ground grid has a good performance of limiting the potential difference of the ground grid.

\section{Ground grid model}

Figure 1 is the structure diagram of the ground grid of a $220-\mathrm{kV}$ substation. The size of the ground grid is $100.5 \mathrm{~m} \times 84 \mathrm{~m}$, and the depth of the ground network buried in the soil is $0.6 \mathrm{~m}$. The soil is homogeneous and monolayer with a resistivity of $130 \Omega \cdot \mathrm{m}$. In this calculation, galvanized flat steel and copper are used as ground mesh materials for calculation, and the material properties are shown in Table 1.

Table 1. The material properties

\begin{tabular}{|c|c|c|c|}
\hline material & resistivity & $\begin{array}{c}\text { relative } \\
\text { permeability }\end{array}$ & size \\
\hline $\begin{array}{c}\text { galvanized flat } \\
\text { steel }\end{array}$ & $1.7 \times 10^{-7} \Omega \cdot \mathrm{m}$ & 1 & $\begin{array}{c}40 \mathrm{~mm} \times \\
4 \mathrm{~mm}\end{array}$ \\
\hline copper & $1.7 \times 10^{-8} \Omega \cdot \mathrm{m}$ & 636 & $\mathrm{r}=7.1 \mathrm{~mm}$ \\
\hline
\end{tabular}

The grounding grid model as shown in figure 1 was

${ }^{*}$ Corresponding author's e-mail:120192201285@ncepu.edu.cn 
established in CDEGS software. The upper-left coordinate of the grounding grid is $(1,1,0.6)$. The square of the $\mathrm{x}$ - and $\mathrm{y}$ - axis points to the long and wide directions of the grounding grid respectively, and the positive direction of the z-axis points vertically to the center of the earth. The coordinates of short-circuit current injection point are $(50,45,0.6)$, and the coordinates of observation points A, B and C are $(60,45,0.6),(90,45,0.6)$ and $(90,80,0.6)$ respectively.

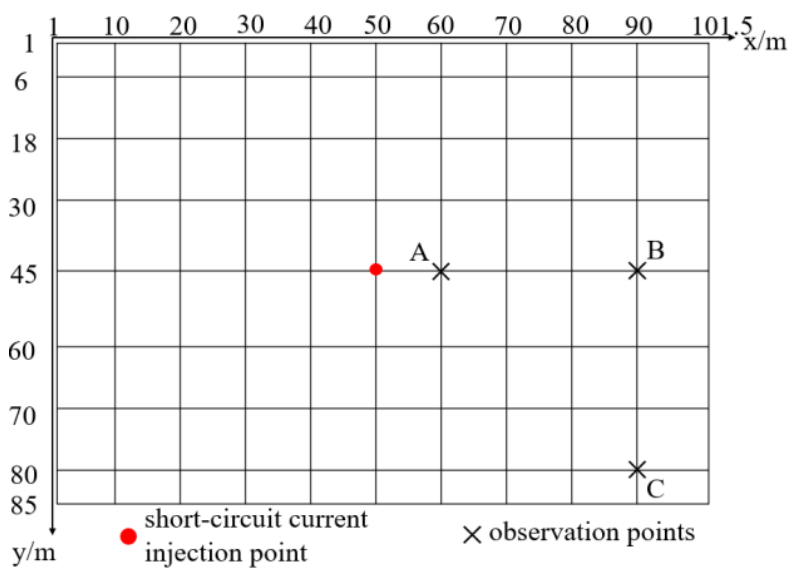

Figure 1. Ground grid model of $220 \mathrm{kV}$ substation

\section{Calculation of short-circuit fault ground potential at different frequencies}

CDEGS software was used to simulate and calculate the grounding grid model shown in Figure 1. The short-circuit current amplitude was set as $20 \mathrm{kA}$ and the current frequency was $1 / 10 / 50 / 100 / 1000 \mathrm{~Hz}$.

\subsection{Impedance of grounding grid and ground potential rise at short circuit point}

Grounding impedance and ground potential rise(GPR) at short circuit point of ground grid at different short-circuit current frequencies are shown in the Table 2 and Figure 2.

It can be seen from Table 2 and Figure 2 that, with the increase of frequency, the grounding impedance and ground potential rise of the grounding grid made of galvanized flat steel show an upward trend, while the calculation results of the grounding grid made of copper are basically not affected by the change of frequency. As can be seen from the results of the last two columns in Table 2, the grounding resistance and ground potential rise ratio of the short-circuit point of the ground grid of the two materials are consistent at different frequencies, indicating that the ground potential rise of the short-circuit point is mainly determined by the grounding impedance of the ground grid.

Table 2. Grounding impedance and GPR of grounding grid at different frequencies

\begin{tabular}{|c|c|c|c|c|c|c|}
\hline \multirow[b]{2}{*}{ Frequency $\quad(\mathrm{Hz})$} & \multicolumn{2}{|c|}{ galvanized flat steel } & \multicolumn{2}{|c|}{ copper } & \multicolumn{2}{|c|}{ ratio (galvanized flat steel/copper) } \\
\hline & $\begin{array}{r}\text { grounding } \\
\text { impedance }(\Omega \text { ) }\end{array}$ & $\begin{array}{l}\text { GPR at short } \\
\text { circuit point }(\mathrm{V})\end{array}$ & $\begin{array}{r}\text { grounding } \\
\text { impedance }(\Omega)\end{array}$ & $\begin{array}{l}\text { GPR at short } \\
\text { circuit point }(\mathrm{V})\end{array}$ & $\begin{array}{r}\text { grounding } \\
\text { impedance }(\Omega)\end{array}$ & $\begin{array}{l}\text { GPR at shor } \\
\text { circuit point }(\mathrm{V})\end{array}$ \\
\hline 1 & 0.6636 & 13272.42 & 0.6587 & 13174.68 & 1.0074 & 1.0074 \\
\hline 10 & 0.6670 & 13340.85 & 0.6588 & 13175.61 & 1.0125 & 1.0125 \\
\hline 50 & 0.6769 & 13537.51 & 0.6590 & 13179.98 & 1.0271 & 1.0271 \\
\hline 100 & 0.6845 & 13690.29 & 0.6593 & 13186.03 & 1.0382 & 1.0382 \\
\hline 1000 & 0.7547 & 15093.39 & 0.6685 & 13369.83 & 1.1289 & 1.1289 \\
\hline
\end{tabular}

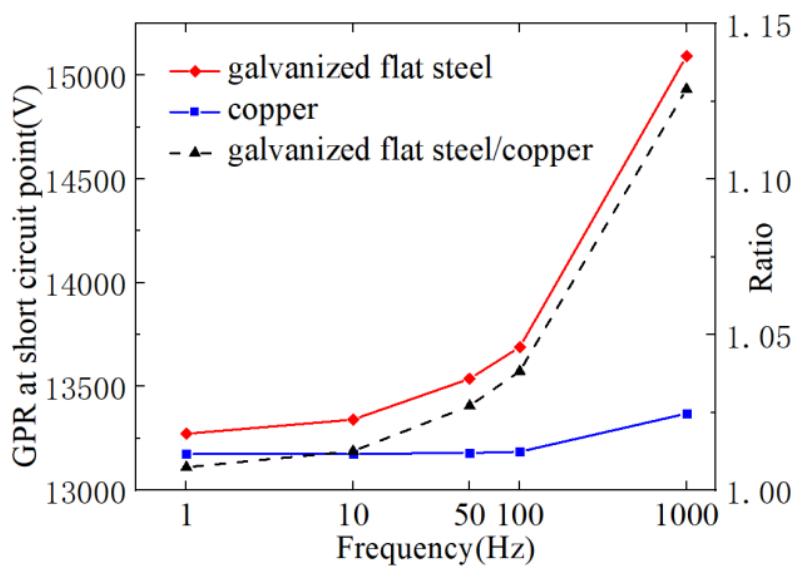

a) GPR at short circuit point

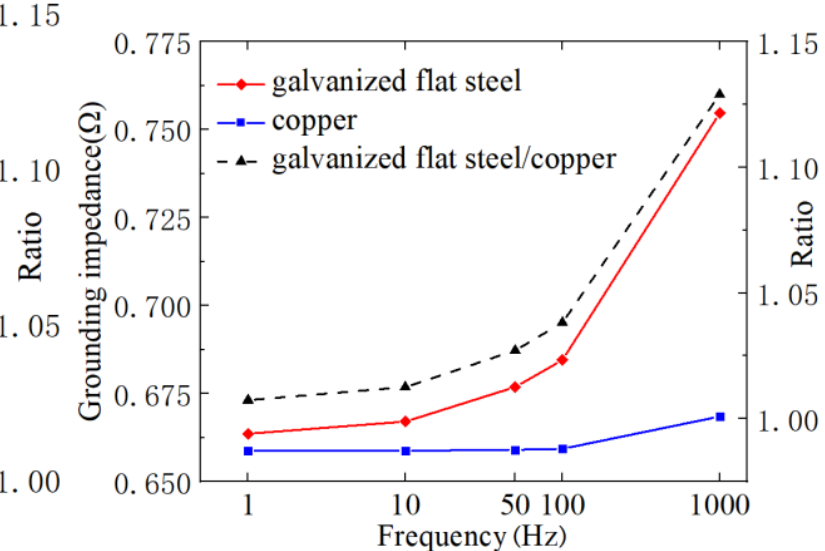

b) Grounding impedance

Figure 2. Grounding impedance and GPR of grounding grid at different frequencies

\subsection{Ground potential difference of grounding grid}

The calculation results of the ground potential difference between two points in the grounding network at different short-circuit current frequencies are shown in Table 3 and Figure 3. It can be seen from the calculation results that using copper instead of galvanized flat steel as ground grid material can reduce the ground potential difference by 10 times in the frequency range of $1 \sim 1000 \mathrm{~Hz}$. The use 
of copper grounding grid has the effect of significantly

reducing the ground potential difference of grounding grid.

Table 3. Ground potential difference between two points of grounding grid

\begin{tabular}{|c|c|c|c|c|c|c|c|}
\hline \multirow[b]{2}{*}{ frequency $(\mathrm{Hz})$} & \multicolumn{3}{|c|}{ galvanized flat steel } & \multicolumn{3}{|c|}{ copper } & \multirow{2}{*}{ 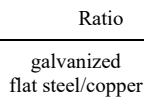 } \\
\hline & $U_{\mathrm{AB}}$ & $U_{\mathrm{BC}}$ & $U_{\mathrm{CA}}$ & $U_{\mathrm{AB}}$ & $U_{\mathrm{BC}}$ & $U_{\mathrm{CA}}$ & \\
\hline 1 & 55.18 & 3.25 & -58.43 & 5.36 & 0.31 & -5.67 & 10.36 \\
\hline 10 & 87.74 & 5.14 & -92.88 & 5.80 & 0.34 & -6.14 & 15.12 \\
\hline 50 & 181.32 & 10.55 & -191.87 & 7.82 & 0.46 & -8.28 & 23.10 \\
\hline 100 & 252.97 & 14.62 & -267.59 & 10.54 & 0.60 & -11.14 & 24.13 \\
\hline 1000 & 867.01 & 45.44 & -912.45 & 80.41 & 3.07 & -83.48 & 12.17 \\
\hline
\end{tabular}

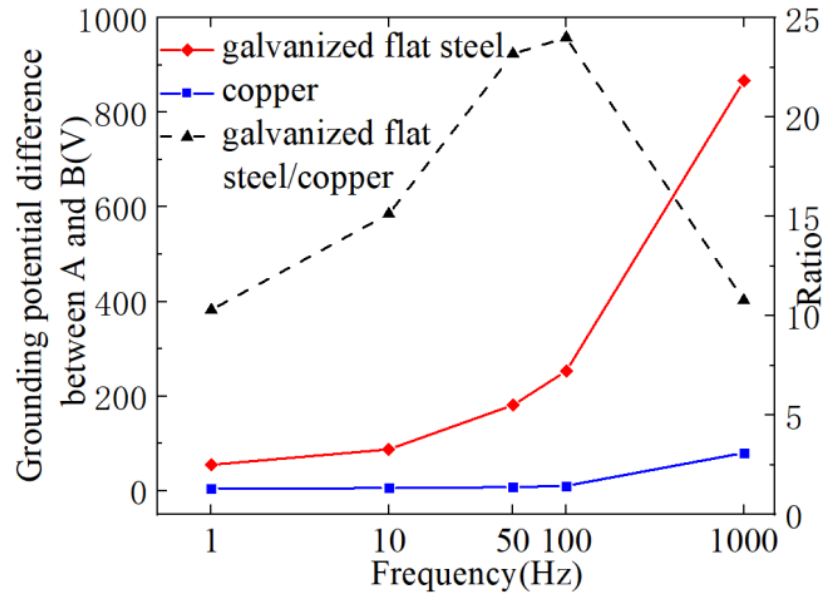

a) Ground potential difference between observation points $\mathrm{A}$ and $\mathrm{B}$

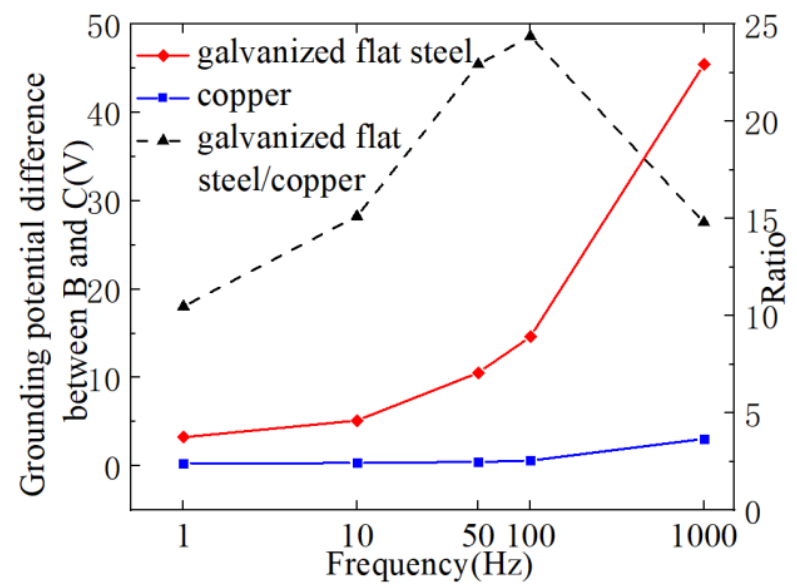

b) Ground potential difference between observation points $\mathrm{B}$ and $\mathrm{C}$

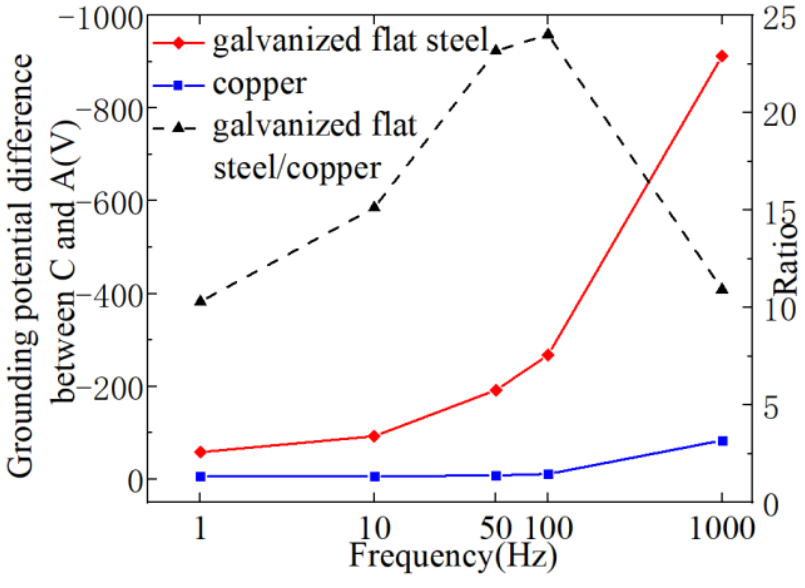

c) Ground potential difference between observation points $\mathrm{C}$ and $\mathrm{A}$

Figure 3. Ground potential difference between two points of grounding grid

\subsection{Distribution characteristics of ground potential rise of grounding grid}

Take the short circuit point as $(50,45,0.6)$, and calculate the ground potential rise of grounding grid at $1 / 50 / 1000 / 10000 \mathrm{~Hz}$. The ground potential rise distribution on the plane $\mathrm{z}=0.6 \mathrm{~m}$ where the ground grid is drawn is shown in figure 4 . As can be seen from Figure 4, when the short-circuit current frequency is low, the ground potential rise is evenly distributed throughout the ground network; with the increase of the frequency, the ground potential rise is gradually concentrated in the area near the shortcircuit point, and the higher the frequency, the more obvious the effect. 


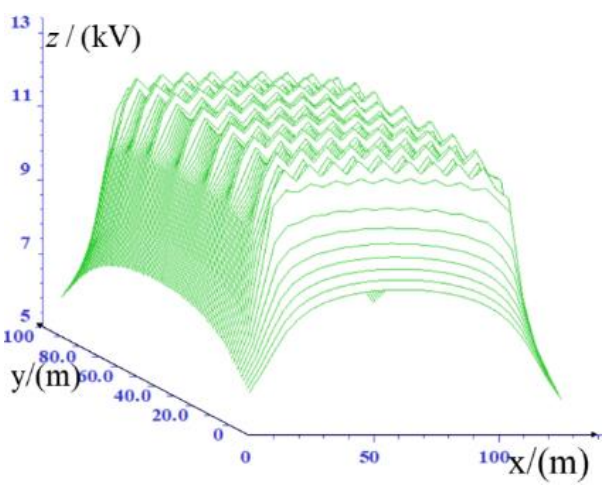

a) Frequency $=1 \mathrm{~Hz}$

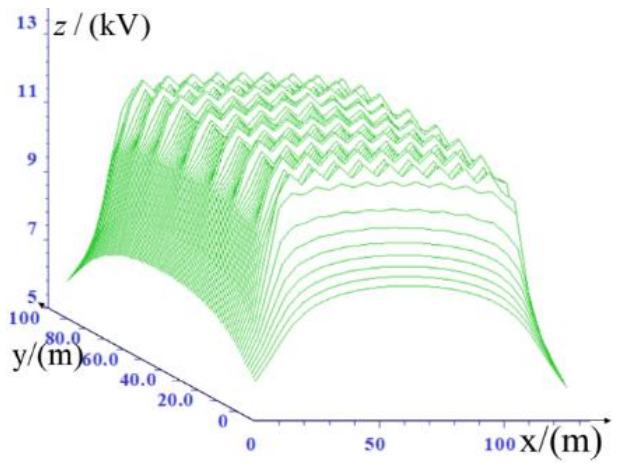

b) Frequency $=50 \mathrm{~Hz}$

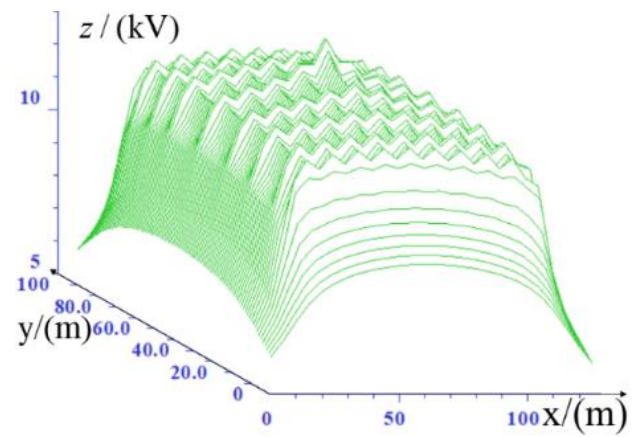

c) Frequency $=1000 \mathrm{~Hz}$

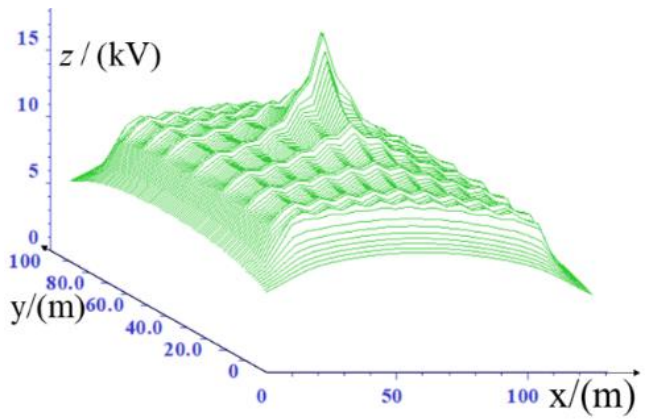

d) Frequency $=10000 \mathrm{~Hz}$

Figure 4. Distribution of ground potential rise in different frequencies

\section{Conclusion}

(1) With the increase of short-circuit current frequency, the grounding impedance and the ground potential at the short-circuit point of the galvanized flat steel grounding grid rise rapidly, while these two parameters of the copper grounding grid remain basically unchanged.

(2) In the range of short-circuit current frequency $1 \sim 1000 \mathrm{~Hz}$, the potential difference between two points of galvanized flat steel grounding grid is more than 10 times that of copper grounding grid.

(3) The higher the short-circuit current frequency is, the more uneven the ground potential distribution is, which is reflected in that the ground potential rise mainly concentrates near the short circuit point.

\section{Acknowledgement}

This project was supported by the Science and Technology Project of SGCC "Research on Outdoor Installation Protection Scheme and Key Technologies."

\section{References}

1. Dong X Z, CHINA T U B, WANG D L, et al. (2016)Smart power substation development in China[J]. CSEE Journal of Power and Energy Systems, 2(4): 1-5.

2. Wang P, Jia L L, Li S X, et al.( 2018) Optimal design of grounding grid for $110 \mathrm{kV}$ whole-indoor intelligent substation[J].Electric Power, 51(3): 42-48.

3. Zhang B, Jiang Y K, Wu J P, et al. (2014)Influence of potential difference within large grounding grid on fault current Division factor[J]. IEEE Transactions on Power Delivery2014, 29(4):17521759.

4. Wu M L, Cui X.(2005) Analysis of Electromagnetic Interference in Shielded Cables Caused by Ground Potential Difference in Substations[J]. High Voltage Engineering,31(3):53-55,60.

5. Lu Z W, Wen X S, Shi Y L, et al. (2003)Numerical calculation of large substation grounding grids in industry frequency $[\mathrm{J}]$. Proceedings of the CSEE, 23(12): 89-93.

6. He J L, Zhang B, Zeng R, (2015)Maximum Limit of Allowable Ground Potential Rise of Substation Grounding System. IEEE Transaction on Industry Applications,51(6):5010-5016. 